\title{
Long-Term Global Irradiance Calibration of Multifilter UV Radiometers
}

\author{
A. A. Piedehierro a AND M. L. CANCillo \\ Departamento de Física, and Instituto Universitario de Investigación del Agua, Cambio Climático y Sostenibilidad, \\ Universidad de Extremadura, Badajoz, Spain \\ J. M. VILAPLANA \\ Departamento de Observación de la Tierra, Teledetección y Atmósfera, Estación de Sondeos \\ Atmosféricos “El Arenosillo,” INTA, Mazagón, Huelva, Spain
}

\author{
A. SERRANO \\ Departamento de Física, and Instituto Universitario de Investigación del Agua, Cambio Climático y Sostenibilidad, \\ Universidad de Extremadura, Badajoz, Spain
}

(Manuscript received 6 August 2018, in final form 7 September 2019)

\begin{abstract}
Multifilter instruments such as the Norwegian Institute for Air Research (NILU)-UV Irradiance Meter (NILU-UV) are suitable for long-term monitoring of UV radiation, as long as their irradiance scale is maintained. The sensitivity of these instruments varies with time; thus, periodic standard absolute calibrations are required. However, standard calibrations may be insufficient to characterize the short-term variations of channels sensitivity. Therefore, results from standard calibrations have to be combined with the information derived from frequent relative calibrations, leading to a stable irradiance scale. This paper focuses on the long-term application of three calibration methods, hereinafter referred to as $\mathrm{CC}, \mathrm{CC} 2$, and $\mathrm{CC} 2(\phi)$, as applied to the NILU-UV 119 multifilter radiometer. Here a generalization is proposed, consisting of using empirical functions in order to guarantee the accurate calibration of multifilter instruments over long time periods. These function-based methods need to be updated regularly to account for changes on instrument sensitivity. The changes in sensitivity of the NILU-UV 119 were found to be channel dependent. The detected drifts range from $23 \%$ to $42 \%$ for a $4-y r$ period of study. Time series of calibrated irradiance are obtained by applying the proposed methods. Results suggest that calibration methods using empirical functions perform better than classic calibration approaches that use constant calibration factors. When methods CC2 and $\mathrm{CC} 2(\phi)$ are applied, calibrated irradiances agree with the measurements of reference within $\pm 5 \%$ for channel 305 and within $\pm 3 \%$ for channels 312,320 , and 340 .
\end{abstract}

\section{Introduction}

Stratospheric ozone and clouds are main factors for the amount of ultraviolet (UV) radiation reaching Earth's surface. Due to the absorption of UV and infrared radiation by ozone, changes in stratospheric ozone affect the temperature profile of the atmosphere, with important long-term consequences for synoptic circulation and climate. Although a partial recovery

\footnotetext{
${ }^{\text {a }}$ Current affiliation: Finnish Meteorological Institute, Helsinki, Finland.

Corresponding author: Ana A. Piedehierro, piedehierro@ unex.es
}

of the ozone layer has been reported (WMO 2014), the effect of gases not regulated by the Montreal Protocol may influence the expected full recovery (Hossaini et al. 2015). Other factors modulating UV radiation (albedo and aerosols) are related to climate change as well. Forthcoming UV level at Earth's surface will be therefore dependent on the changing amount of ozone, cloudiness, albedo and aerosols. Thus, monitoring these modulating factors and UV level become essential to understand the interaction among them and foresee the future UV scenario. The long-term monitoring of UV radiation at ground level requires very accurate instrumentation, sensitive to small variations in UV level, and stable for long periods of time (Lucas et al. 2015). 
Multifilter radiometers (also known as multichannel or narrowband filter instruments) are well suited to achieve some of the objectives that require long periods of UV radiation measurements: establishing a UV climatology, detecting trends in global UV irradiance, and gaining information about current UV levels and their diurnal and seasonal variability (Díaz et al. 2011). Multifilter radiometers measure in several discrete bands with high temporal frequency. They can be used to derive biologically effective doses, total ozone column and cloud attenuation (Seckmeyer et al. 2010).

There are several approaches to calibrate multifilter instruments, applying different procedures (comparison with spectroradiometers or lamps, empirical approaches), and focusing on one of a variety of radiometric quantities (spectral or response-weighted irradiance, UV dose rates). An overview of different calibration methodologies was compiled by Seckmeyer et al. (2010).

Notable efforts have been made to standardize the calibration methodologies applicable to multifilter radiometers by using similar concepts to those developed for the calibration of broadband radiometers and spectroradiometers (Gröbner et al. 1996, 2006; Webb et al. 2006). The pioneering work by Dahlback (1996) established the basis for calibrating multifilter instruments, defining a methodology that uses a constant as an absolute calibration term. Subsequent studies by Høiskar et al. (2003) and Johnsen et al. (2008a) focused on including angular dependencies, similarly to the aforementioned methodologies developed for spectroradiometers and broadband instruments.

A comparison between different calibration methodologies focused on response-weighted irradiance was carried out by Piedehierro et al. (2016). It included four methods: the original Dahlback equation (DB), the cosine corrected method (CC), and improved versions of both of them (DB2 and CC2), with an empirical function playing the role of the absolute calibration term. Results from Piedehierro et al. (2016) evidenced that the application of methods based on empirical functions reduces the uncertainty in calibrated irradiance at large solar zenith angle (SZA), specially for channels 305 and 320 . These channels mean a main contribution to the calculation of total ozone column and different biological UV dose rates from multifilter instrument data. However, the response of multifilter instruments degrades with time as a result of changes in their optical elements. Although changes in the spectral response functions (SRF) may occur, the main cause for raw signal drifting is the change in the absolute sensitivity of the channels. It has been documented that responsivities of some multifilter instruments [such as the Norwegian Institute for Air Research
(NILU)-UV Irradiance Meter (NILU-UV) and the Ground-Based Ultraviolet/PAR Radiometer (GUV)] have drifted between $7 \%$ and $40 \%$ over a $2-3$-yr period (Bernhard et al. 2008; Lakkala et al. 2005; Meinander et al. 2004; Fan et al. 2014; Norsang et al. 2009, 2014; Kazantzidis et al. 2006). Therefore, any calibration performed at a certain date may get outdated in a relatively short period of time, thus requiring frequent calibrations. Standard calibrations against a reference spectroradiometer are strongly recommended to be performed once per year (Seckmeyer et al. 2010). In those standard calibrations, the absolute calibration term is recalculated and an updated value is obtained. Nevertheless, standard calibrations seem to be insufficient for accounting for sensitivity changes between standard calibrations since drifts may be nonlinear (Lakkala et al. 2005). Irradiance scale can be maintained between standard calibrations by carrying out relative calibrations based on lamp tests. These relative calibrations can be used to correct short-term sensitivity drifts and maintain accurate measurements in the long term.

Results from relative calibrations are easily included in the DB-based calibration methodologies as a drift factor that scales the value of the absolute calibration constant (Lakkala et al. 2005; Meinander et al. 2004; Fan et al. 2014; Norsang et al. 2009, 2014; Kazantzidis et al. 2006). Johnsen et al. (2008b) specified how to retrieve daily drift factors from consecutive calibrations (standard or relative) by linear interpolation.

However, calibration methods that include empirical functions as the absolute calibration term cannot be easily generalized for a long period of time. As formulated, these empirical functions cannot be linearly interpolated or easily matched to the results of relative calibrations.

Within this context, the present work proposes a generalization to a long-term scale that adapts the applicability of different calibration methods based on the use of an empirical function as the absolute calibration term, such as CC2. To our knowledge, this type of generalization has never been addressed before.

In addition, a comparative analysis of the long-term generalized methods $\mathrm{CC}$ and $\mathrm{CC} 2$ is performed, assessing the accuracy that can be expected from their application.

The paper is structured as follows. In section 2, the NILU-UV radiometer and the Brewer spectroradiometer used in this work are described. In section $3, \mathrm{CC}$ and $\mathrm{CC} 2$ equations are described and their generalization is presented. Section 4 compares the performance of the generalized equations and describes how their terms are obtained. Finally, in the last section, the main conclusions are compiled. 


\section{Instruments and data}

The study carried out in this work comprises four years of measurements (July 2011 to June 2015) of the NILU-UV 119 multifilter instrument and the collocated reference spectroradiometer Brewer 150. These instruments are installed at El Arenosillo Atmospheric Observatory, which belongs to the Earth Observation and Atmosphere Department, National Institute for Aerospace Technology (INTA). This observatory is located near Mazagón, Spain $\left(37.1^{\circ} \mathrm{N}, 6.7^{\circ} \mathrm{W}, 41 \mathrm{~m}\right.$ above sea level), and participates as station 213 in the Global Ozone Observing System of the Global Atmosphere Watch program of the World Meteorological Organization. This observatory is equipped with additional instrumentation for measuring ozone and radiation (Brewer and Dobson spectrometers, NILU-UV and GUV multifilter instruments, UV sensors, pyranometers, and pyrgeometers). Moreover, a fully equipped calibration laboratory can be found at INTA El Arenosillo observatory, facilitating the spectral and angular characterization of instrumentation.

\section{a. NILU-UV multifilter radiometer}

The instrument studied in this work is the NILU-UV 119 multifilter radiometer. It belongs to the Atmósfera Clima y Radiación de Extremadura (AIRE) research group (University of Extremadura, Badajoz, Spain) but it has been in operation at INTA El Arenosillo observatory since its acquisition in 2007.

The NILU-UV 119 measures radiation in five moderate bandwidth channels ( $10 \mathrm{~nm}$ full width at half maximum) and has an additional channel sensitive to photosynthetically active radiation. This radiometer is very versatile, being able to provide estimations of several UV dose rates, total ozone column and cloud optical depth.

NILU-UV 119 has been calibrated using the same protocol since July 2011, described in detail by Piedehierro et al. (2016) and Piedehierro (2016). The spectral and angular responses for these calibrations were determined at INTA El Arenosillo laboratory, and the absolute calibration terms were obtained by intercomparison with the Brewer 150 spectroradiometer. Moreover, it has participated in the biennial intercomparison campaigns of the Regional Brewer Calibration Center-Europe since 2011, with the Quality Assurance of solar Spectral Ultraviolet irradiance Measurements carried out in Europe (QASUME) unit providing additional data for absolute calibration.

\section{b. Brewer spectroradiometer}

The Brewer 150 spectroradiometer (MK-III), in operation at INTA El Arenosillo observatory since 1997, has been used as the reference in this study. It measures global UV spectra $(290-363 \mathrm{~nm})$ with $0.5 \mathrm{~nm}$ spectral resolution and $0.05 \mathrm{~nm}$ wavelength accuracy. It also measures total ozone amount.

The UV J1015 entrance optic of this spectroradiometer (developed by CMS Ing. Dr. Schreder $\mathrm{GmbH}$ ) has a very small cosine error compared with traditional flat diffusers (Gröbner 2003).

The maintenance and quality assurance of the Brewer measurements are achieved by performing internal lamp tests with a mercury lamp and a $20 \mathrm{~W}$ halogen lamp. In addition to these tests, the spectroradiometer is periodically calibrated against a $1000 \mathrm{~W}$ quartz-halogen NIST-traceable standard lamp (DXW model), with 5\% associated uncertainty (Vilaplana 2004). Besides, the Brewer 150 has participated in the biennial intercomparison campaigns of the Regional Brewer Calibration Center-Europe since 1999. Intercomparisons with the QASUME unit between 2011 and 2015 set an estimation for the UV spectra uncertainties measured by the Brewer spectroradiometer: for wavelengths between 300 and $310 \mathrm{~nm}$ the uncertainties are $11.5 \%$ and $8.6 \%\left(\mathrm{SZA}<75^{\circ}\right.$ and SZA $<50^{\circ}$, respectively); for wavelengths larger than $310 \mathrm{~nm}$ the uncertainties are reduced to $7.0 \%$ and $6.6 \%$ for the same SZA ranges mentioned earlier.

\section{c. NILU-UV 119 laboratory characterization}

The NILU-UV 119 instrument has been spectrally and angularly characterized at INTA El Arenosillo laboratory during the period 2011-15.

\section{1) SPECTRAL RESPONSE}

The relative SRF for each channel of the NILU-UV 119 radiometer was determined in 2011, 2013, and 2015 (Fig. 1), using the methodology and facilities described by Piedehierro et al. (2016) and Piedehierro (2016). In 2013 the operating temperature of this instrument was increased from $40^{\circ}$ to $50^{\circ} \mathrm{C}$, and the SRFs were measured before and after the change in temperature.

Results for the peak nominal $\left(\lambda_{\max }\right)$ and centroid $\left[\lambda_{c}\right.$, defined in Eq. (1)] wavelengths for all these characterizations are compiled in Table 1 :

$$
\lambda_{c}=\frac{\int_{0}^{\infty} E(\lambda) \lambda d \lambda}{\int_{0}^{\infty} E(\lambda) d \lambda} .
$$

Variations detected in $\lambda_{\max }$ for the 2011-15 characterizations are within the uncertainty interval of the SRFs determination (less than $0.5 \mathrm{~nm}$ at maximum). Moreover, variations in $\lambda_{c}$ are less than $0.4 \mathrm{~nm}$ for all channels and calibrations. Therefore, it is possible to state that 


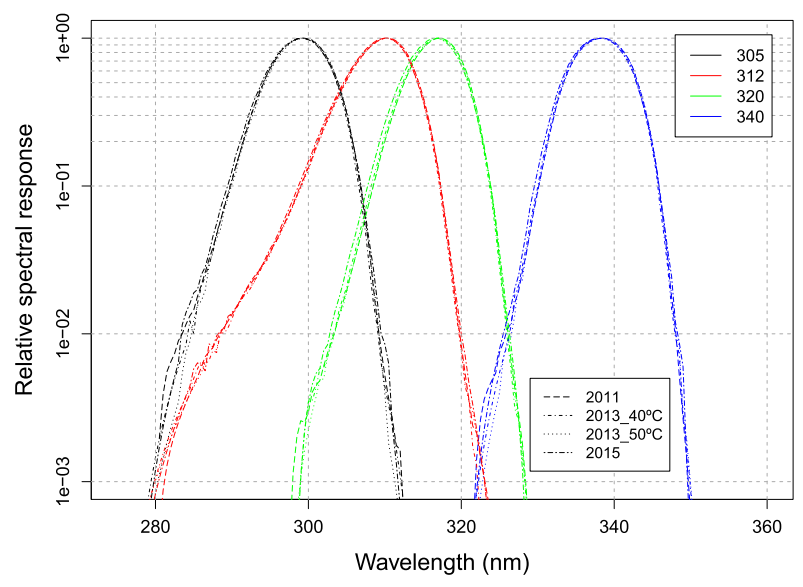

FIG. 1. Relative spectral response functions for NILU-UV 119 determined in 2011, 2013, and 2015.

the SRFs remained unchanged for the study period. Consequently, SRFs measured in 2011 will be used for further calculations.

\section{2) ANGULAR RESPONSE}

The most comprehensive angular response determination for the NILU-UV 119 instrument was carried out in 2012, when both north-south and east-west planes were characterized. The angular response and, therefore, the cosine error were measured using a light source illuminating the entrance optic of the NILU-UV radiometer under different angles of incidence. Details on the setup and methodology applied are described by Piedehierro (2016). The cosine error measured at four orientations (north, south, east, west) was found to be azimuthally dependent with the dependence varying with the channel (Fig. 2). However, regardless of the azimuthal dependence, the cosine error is smaller than $5 \%$ for $\mathrm{SZA}<60^{\circ}$ and smaller than $10 \%$ for $\mathrm{SZA}<80^{\circ}$. These results are in agreement with those shown for NILU-UV instruments by Kazantzidis et al. (2006).

\section{Methods}

A term for correcting the cosine error (COSCOR) should be included in the calibration equation
(Piedehierro et al. 2016). For its determination, the measurement of the angular response carried out in a calibration laboratory is needed. Moreover, the measurement of the angular response is strongly recommended since it would also serve as a benchmark for optimization of the spectral response function, meaning that if, after applying the COSCOR function the angular dependencies still persist, the SRFs could have been inaccurately determined. In conclusion, methods including the cosine correction term COSCOR will lead to more accurate values of calibrated irradiances compared to those not including the COSCOR term. Therefore, this section focuses on describing the generalization for the long-term application of methods $\mathrm{CC}$ and $\mathrm{CC} 2$. Methods based on an absolute calibration factor DB, DB2 (Piedehierro et al. 2016) may be generalized following the procedure here presented.

\section{a. Generalized calibration methods}

As emphasized in the introduction, since calibration equations are obtained at a specific date, they are not applicable for an extended period of time due to changes in sensitivity produced by changes in SRF, angular responses or absolute sensitivity. In the case that SRF varies, COSCOR and the absolute calibration term need to be recalculated (Webb et al. 2006; Dahlback 1996). Additionally, if the angular performance of the radiometer changes, new COSCOR functions will have to be obtained, affecting the absolute calibration term. However, it was found that the SRFs remained stable for the NILU-UV 119 during the period 2011-15, as well as the angular responses, as discussed in previous sections $2 c(1)$ and $2 c(2)$. Thus, the methodology to adapt the calibration equations for their long-term use should focus on the variation of the absolute calibration term as a result of the changing absolute sensitivity of the channels.

\section{1) Generalized CC $[\mathrm{CC}(\mathrm{T})]$}

The original CC calibration method [Eq. (2)] is an adaptation for multifilter radiometers (Piedehierro et al. 2016) of the broadband radiometers calibration methodology:

TABLE 1. Peak nominal $\left(\lambda_{\max }\right)$ and centroid $\left(\lambda_{c}\right)$ wavelengths of the NILU-UV 119 SRFs from 2011, 2013 , and 2015.

\begin{tabular}{|c|c|c|c|c|c|c|c|c|}
\hline \multirow[b]{2}{*}{ Channel } & \multicolumn{2}{|c|}{2011} & \multicolumn{2}{|c|}{$2013\left(40^{\circ} \mathrm{C}\right)$} & \multicolumn{2}{|c|}{$2013\left(50^{\circ} \mathrm{C}\right)$} & \multicolumn{2}{|c|}{2015} \\
\hline & $\begin{array}{c}\lambda_{\max }(\mathrm{nm}) \\
\pm 0.5 \mathrm{~nm}\end{array}$ & $\begin{array}{l}\lambda_{c}(\mathrm{~nm}) \\
\pm 0.5 \mathrm{~nm}\end{array}$ & $\begin{array}{c}\lambda_{\max }(\mathrm{nm}) \\
\pm 0.5 \mathrm{~nm}\end{array}$ & $\begin{array}{l}\lambda_{c}(\mathrm{~nm}) \\
\pm 0.5 \mathrm{~nm}\end{array}$ & $\begin{array}{c}\lambda_{\max }(\mathrm{nm}) \\
\pm 0.5 \mathrm{~nm}\end{array}$ & $\begin{array}{l}\lambda_{c}(\mathrm{~nm}) \\
\pm 0.5 \mathrm{~nm}\end{array}$ & $\begin{array}{c}\lambda_{\max }(\mathrm{nm}) \\
\pm 0.5 \mathrm{~nm}\end{array}$ & $\begin{array}{l}\lambda_{c}(\mathrm{~nm}) \\
\pm 0.5 \mathrm{~nm}\end{array}$ \\
\hline 305 & 299.0 & 298.6 & 299.0 & 298.5 & 299.5 & 298.7 & 299.0 & 298.5 \\
\hline 312 & 310.5 & 308.7 & 310.0 & 308.6 & 310.5 & 308.7 & 310.0 & 308.5 \\
\hline 320 & 317.0 & 316.5 & 317.0 & 316.3 & 317.0 & 316.4 & 316.5 & 316.1 \\
\hline 340 & 338.5 & 338.1 & 338.5 & 338.0 & 338.5 & 338.1 & 338.0 & 337.8 \\
\hline
\end{tabular}



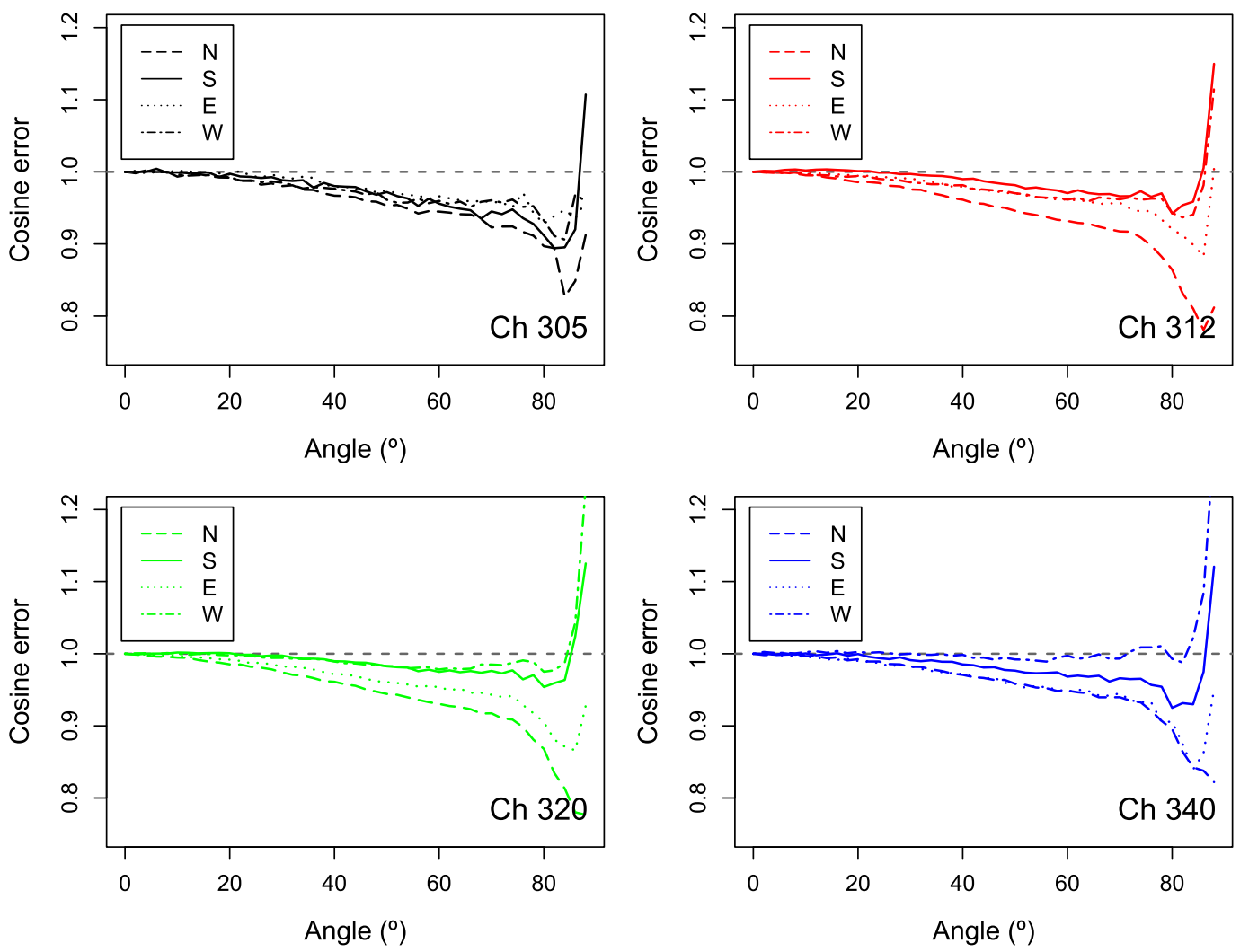

FIG. 2. Cosine error for NILU-UV 119 determined in 2012 at four azimuthal orientations.

$$
E_{i}=K_{i}^{\prime} U_{i}^{\mathrm{net}} \operatorname{COSCOR}_{i}(\theta, \phi),
$$

where $E_{i}$ is the spectral irradiance at Earth's surface measured by the Brewer spectroradiometer weighted by the spectral response of the channel $i\left(\mathrm{~W} \mathrm{~m}^{-2}\right), U_{i}^{\text {net }}$ is the radiometer net signal for the channel $i$ (counts), and $\operatorname{COSCOR}_{i}(\theta, \phi)$ is the cosine correction function (dimensionless). It rectifies the mismatch between the actual angular response of a radiometer and the expected ideal behavior, given by the cosine law (being $\theta, \phi$ the SZA and the solar azimuthal angle, respectively). Here, $K_{i}^{\prime}$ is the angular-corrected calibration coefficient for channel $i\left(\mathrm{~W} \mathrm{~m}^{-2}\right.$ counts $\left.^{-1}\right)$, determined as the average of a set of $n$ instantaneous values $K_{i j}^{\prime}$ obtained during an intercomparison period between the multifilter instrument and the reference Brewer spectroradiometer. It is calculated as follows:

$$
K_{i}^{\prime}=\frac{1}{n} \sum_{j=1}^{n} k_{i j}^{\prime}=\frac{1}{n} \sum_{j=1}^{n} \frac{E_{i j}}{U_{i j}^{\text {net }} \operatorname{COSCOR}_{i}(\theta, \phi)},
$$

where $E_{i j}$ are the spectrally weighted Brewer irradiances for channel $\mathrm{i}$, and $U_{i j}^{\text {net }}$ are the simultaneous records of the NILU-UV.

The calculation of the COSCOR function is described by Gröbner et al. (1996) and Johnsen et al. (2008a) and details of the determination for our instrument can be found in Piedehierro et al. (2016).

The CC method can be promptly generalized for long-term use: temporal variations of $K_{i}^{\prime}$ must be taken into account as $K_{i}^{\prime}(t)$, leading to this general equation:

$$
E_{i}(t)=K_{i}^{\prime}(t) U_{i}^{\text {net }} \operatorname{COSCOR}_{i}(\theta, \phi)
$$

$K_{i}^{\prime}(t)$ may be evaluated in two ways: by periodic intercomparisons with a reference spectroradiometer or by relative calibrations based on lamps. The most accurate calibration results are expected from frequent $K_{i}^{\prime}$ determination regardless of the method used. The hightemporal-resolution reconstruction of $K_{i}^{\prime}(t)$ is obtained by linear interpolation of consecutive $K_{i}^{\prime}$ values.

The relative calibration methodology used in this work is the one recommended by the manufacturer of the NILU-UV relative lamp unit (NILU Products 1999), and is based on lamp calibrations. The NILU-UV radiometer is exposed to several stable sources of UV radiation (three 100-W Osram lamps), and its output signal is recorded and compared between consecutive relative calibrations. Temporal variations in the output signal indicate changes in the sensitivity of the instrument 
channels. Piedehierro (2016) evaluated the associated uncertainty of this methodology $(0.5 \%)$ by carrying out several lamp tests in a single day. Further information about the relative calibration unit and methodology can be found in Piedehierro (2016).

\section{2) Generalized CC2 [CC2(T)]}

The CC2 method requires a more complex process for its generalization. The initial formulation (Piedehierro et al. 2016) [Eq. (5)] uses the empirical function $f_{i}^{\prime}(\theta)$ playing the role of both the absolute calibration term and an additional angular correction function, complementary to COSCOR. While COSCOR corrects for angular errors strictly due to geometrical reasons, $f_{i}^{\prime}(\theta)$ corrects for those unsolved angular errors from not well-identified sources (e.g., mismatches in the SRF determination), not taken into account by COSCOR. The term $f_{i}^{\prime}(\theta)$ is derived by fitting the $k_{i j}^{\prime}$ values [defined in Eq. (3)]:

$$
E_{i}(t)=f_{i}^{\prime}(\theta) U_{i}^{\text {net }} \operatorname{COSCOR}_{i}(\theta, \phi) .
$$

Generalizing the formulation of $\mathrm{CC} 2$ to include changes in sensitivity over time is more difficult than for the CC method. First, $f_{i}^{\prime}(\theta)$ is only obtainable by performing absolute calibrations against a calibrated spectroradiometer, and relative calibration information would not be suitable for tracking the variations of this term. Furthermore, it would be difficult to obtain a generalized $f_{i}^{\prime}(\theta, t)$ by interpolating successive individual $f_{i}^{\prime}(\theta)$ functions.

Instead, we modified the original $\mathrm{CC} 2$ equation by splitting the $f_{i}^{\prime}(\theta, t)$ term into a function dependent on time $C_{i}(t)$ and a normalized function $f_{\text {in }}^{\prime}(\theta)$, dependent on SZA:

$$
E_{i}(t)=C_{i}(t) f_{\mathrm{in}}^{\prime}(\theta) U_{i}^{\mathrm{net}} \operatorname{COSCOR}_{i}(\theta, \phi) .
$$

This generalization assumes that the angular correction term $f_{\text {in }}^{\prime}(\theta)$ is constant while changes over time are parameterized with the function $C_{i}(t)$.

To obtain $C_{i}(t)$, successive values of $C_{i}$ are linearly interpolated. The $C_{i}$ individual values are obtained for each period of intercomparison of the multifilter instrument against the reference Brewer. For each period and channel $i, C_{i}$ is calculated as the average of a $k_{i j}^{\prime}$ subset. This subset corresponds to those $k_{i j}^{\prime}$ values that differ by $\pm 2 \%$ from the median value of the $k_{i j}^{\prime}$ whole set. Once $C_{i}$ individual factors are known for all channels, $k_{i j}^{\prime}$ values are normalized for each intercomparison period: particular values of $C_{i}(t)$ and $f_{\text {in }}^{\prime}(\theta)$ are obtained from the same set of $k_{i j}^{\prime}$ values than $f_{i}^{\prime}(\theta)$. First, $C_{i}$ (which is considered as a normalization constant) is calculated as the average of the subset of $k_{i j}^{\prime}$ values that fall within the $\pm 2 \%$ interval around the median value. Once $C_{i}$ constants are known for all channels, $k_{i j}^{\prime}$ values are normalized:

$$
k_{i j n}^{\prime}=\frac{k_{i j}^{\prime}}{C_{i}} .
$$

The empirical function, $f_{\text {in }}^{\prime}(\theta)$, is obtained by fitting all normalized values, $k_{i j n}^{\prime}$, available from successive intercomparisons to a polynomial function dependent on $\cos (\theta)$, given by Eq. (8):

$$
f_{\text {in }}^{\prime}(\theta)=a_{0}+a_{1} \cos (\theta)+a_{2} \cos ^{2}(\theta)+a_{3} \cos ^{3}(\theta) .
$$

According to $\mathrm{CC} 2(t)$ formulation, $C_{i}(t)$ plays the same role as $K_{i}^{\prime}(t)$ in the $\mathrm{CC}(t)$ method. Therefore, relative calibrations contribute to track the temporal variations of $C_{i}$. Since the empirical function $f_{\text {in }}^{\prime}(\theta)$ is obtained from all available $k_{i j n}^{\prime}$ values, it is unique for every instrument channel.

\section{3) $\mathrm{CC} 2(\Phi)$ VERSION}

Preliminary application of $\mathrm{CC} 2(\mathrm{t})$ in this study showed widely scattered $k_{i j n}^{\prime}$ values, particularly for channel 305 at large SZA. This performance is most likely due to the influence of thermal offset in the net signal of this channel for rising and setting sun (Piedehierro et al. 2016). To improve the angular modeling of $k_{i j n}^{\prime}$, the solar azimuthal angle $\phi$ has been taken into account. Thus, the fitting of the empirical function is carried out for two separate datasets: 1 ) $\phi<180^{\circ}$ and 2) $\phi>180^{\circ}$, resulting in two functions for each channel: $f_{\text {in }}^{\prime}\left(\theta, \phi<180^{\circ}\right)$ and $f_{\text {in }}^{\prime}\left(\theta, \phi>180^{\circ}\right)$. This new $\operatorname{CC} 2(\phi)$ version is given by the following equation:

$$
E_{i}(t)=C_{i}(t) f_{\text {in }}^{\prime}(\theta, \phi) U_{i}^{\text {net }} \operatorname{COSCOR}_{i}(\theta, \phi) .
$$

\section{b. Validation methodology}

To obtain the terms for the three methods [CC, CC2, $\mathrm{CC} 2(\phi)]$, a set of 43 7-day intercomparison periods $(N=8100)$ were used to evaluate $K_{i}^{\prime}(t), C_{i}(t), f_{\text {in }}^{\prime}(\theta)$, and $f_{\text {in }}^{\prime}(\theta, \phi)$. An independent dataset $(N=20400)$ was used to validate all three calibration methods $\mathrm{CC}, \mathrm{CC} 2$ and $\mathrm{CC} 2(\phi)$. The relative mean bias error (MBE) and the relative mean absolute bias error (MABE) were used as statistical parameters to evaluate the performance of the calibration methods [Eqs. (10) and (11)]:

$$
\mathrm{MABE}=\frac{1}{N} \sum_{j=1}^{N}\left|\frac{\operatorname{model}_{i j}-\operatorname{ref}_{i j}}{\operatorname{ref}_{i j}}\right| 100,
$$


TABLE 2. Calibration periods selected for this study. Those coincident with biennial intercomparison campaigns of the Regional Brewer Calibration Center-Europe are highlighted in bold.

\begin{tabular}{|c|c|c|c|c|c|c|c|}
\hline Period No. & Period starts & Period ends & $N$ data & Period No. & Period starts & Period ends & $N$ data \\
\hline 1 & 7 Jul 2011 & 13 Jul 2011 & 105 & 23 & 10 Jun 2013 & 21 Jun 2013 & 149 \\
\hline 2 & 24 Sep 2011 & 30 Sep 2011 & 225 & 24 & 18 Jul 2013 & 26 Jul 2013 & 277 \\
\hline 3 & 25 Oct 2011 & 31 Oct 2011 & 181 & 25 & 22 Aug 2013 & 30 Aug 2013 & 258 \\
\hline 4 & 24 Nov 2011 & 30 Nov 2011 & 158 & 26 & 24 Sep 2013 & 30 Sep 2013 & 217 \\
\hline 5 & 25 Dec 2011 & 31 Dec 2011 & 121 & 27 & 25 Oct 2013 & 31 Oct 2013 & 187 \\
\hline 6 & 25 Jan 2012 & 31 Jan 2012 & 152 & 28 & 28 Nov 2013 & 4 Dec 2013 & 120 \\
\hline 7 & 15 Feb 2012 & 21 Feb 2012 & 197 & 29 & 21 Jan 2014 & 27 Jan 2014 & 158 \\
\hline 8 & $25 \operatorname{Mar} 2012$ & 31 Mar 2012 & 222 & 30 & 22 Feb 2014 & 28 Feb 2014 & 203 \\
\hline 9 & 17 Apr 2012 & 23 Apr 2012 & 243 & 31 & 24 Mar 2014 & 30 Mar 2014 & 243 \\
\hline 10 & 25 May 2012 & 31 May 2012 & 203 & 32 & 24 Apr 2014 & 30 Apr 2014 & 270 \\
\hline 11 & 24 Jun 2012 & 30 Jun 2012 & 229 & 33 & 15 Jun 2014 & 21 Jun 2014 & 316 \\
\hline 12 & 25 Jul 2012 & 31 Jul 2012 & 229 & 34 & 24 Jul 2014 & 29 Jul 2014 & 246 \\
\hline 13 & 16 Aug 2012 & 21 Aug 2012 & 166 & 35 & 24 Aug 2014 & 30 Aug 2014 & 253 \\
\hline 14 & 14 Sep 2012 & 20 Sep 2012 & 182 & 36 & 24 Sep 2014 & 30 Sep 2014 & 232 \\
\hline 15 & 17 Oct 2012 & 23 Oct 2012 & 166 & 37 & 17 Oct 2014 & 23 Oct 2014 & 197 \\
\hline 16 & 22 Nov 2012 & 29 Nov 2012 & 113 & 38 & 24 Nov 2014 & 30 Nov 2014 & 125 \\
\hline 17 & 25 Dec 2012 & 31 Dec 2012 & 94 & 39 & 25 Dec 2014 & 31 Dec 2014 & 92 \\
\hline 18 & 25 Jan 2013 & 31 Jan 2013 & 132 & 40 & 19 Jan 2015 & 25 Jan 2015 & 145 \\
\hline 19 & 22 Feb 2013 & 28 Feb 2013 & 172 & 41 & 13 Mar 2015 & 19 Mar 2015 & 216 \\
\hline 20 & 16 Mar 2013 & 22 Mar 2013 & 189 & 42 & 14 Apr 2015 & 20 Apr 2015 & 275 \\
\hline 21 & 13 Apr 2013 & 21 Apr 2013 & 152 & 43 & 2 Jun 2015 & 9 Jun 2015 & 218 \\
\hline 22 & 15 May 2013 & 21 May 2013 & 76 & & & & \\
\hline
\end{tabular}

$$
\mathrm{MBE}=\frac{1}{N} \sum_{j=1}^{N} \frac{\operatorname{model}_{i j}-\operatorname{ref}_{i j}}{\operatorname{ref}_{i j}} 100 .
$$

\section{Results and discussion}

\section{a. Calibration periods}

To study the long-term performance of the NILU-UV 119 (i.e., the temporal evolution of the absolute calibration factors $K^{\prime}$ and $C$ ), intercomparison periods against the Brewer 150 spectroradiometer were selected. Specifically, from all data available, the last week (approximately 7 days) of every month (Table 2) was selected as intervals to assess the variability of $K^{\prime}$ and $C$, resulting in a total of 43 intercomparison periods. Periods 1, 23, and 43 coincide with the international intercomparison campaigns of the Regional Brewer Calibration Center-Europe.

\section{b. $K_{i}^{\prime}$ and $C_{i}$ calibration factors}

The $k_{i j}^{\prime}$ values were calculated for all channels and intercomparison periods. Then $K_{i}^{\prime}$ factors were determined, and $C_{i}$ values were obtained following the methodology specified in section $3 \mathrm{a}(2)$. Their temporal evolution (shown in Fig. 3) was determined by intercomparison with the reference Brewer instead of by relative calibrations, since the relative calibration device was only occasionally available. However, in practice, lamp-based relative calibrations should be used to assess the sensitivity drifts for those periods in between standard calibrations.

The $K_{i}^{\prime}$ and $C_{i}$ factors have very similar absolute values and temporal variations. However, $C_{i}$ is generally higher than $K_{i}^{\prime}$ for the same intercomparison period. The increase of $K_{i}^{\prime}$ and $C_{i}$ with time is an indicator of the sensitivity loss experienced by all channels of the instrument during the entire study period. Nevertheless, the variation of the calibration factors shows fluctuations, reproduced by all channels in the same direction. This fact suggests a common source as the origin of the fluctuations, such as the degradation of the Teflon diffuser (Lakkala et al. 2005). Channels 305 and 320 suffer the largest variations in $K_{i}^{\prime}$ and $C_{i}$ (around $40 \%$ ) for this 4-yr period, while channel 340 shows the most stable performance, with only a $23 \%$ change. Variation ranges for all channels can be found in Table 3 . These results are in agreement with previous studies by other authors. Norsang et al. (2009) found a linear drift of $13.4 \%$ in the UV-B channels for their NILU-UV instrument during 3.5 years of measurements. In the 4-yr study by Lakkala et al. (2005), three Antarctic NILU-UV drifted differently, but reached drifting values up to $40 \%$ for channels 312, 320, and 340. Kazantzidis et al. (2006) reported drifts up to $20 \%$ for channel 340 of a NILU-UV in a $2-y r$ period, while UV-B channels varied within $10 \%$. Norsang et al. (2014) detected a drift of about $25 \%$ for channels 320 and 340 , and of about $20 \%$ for channels 305 and 312 for a NILU-UV operating for two years in 

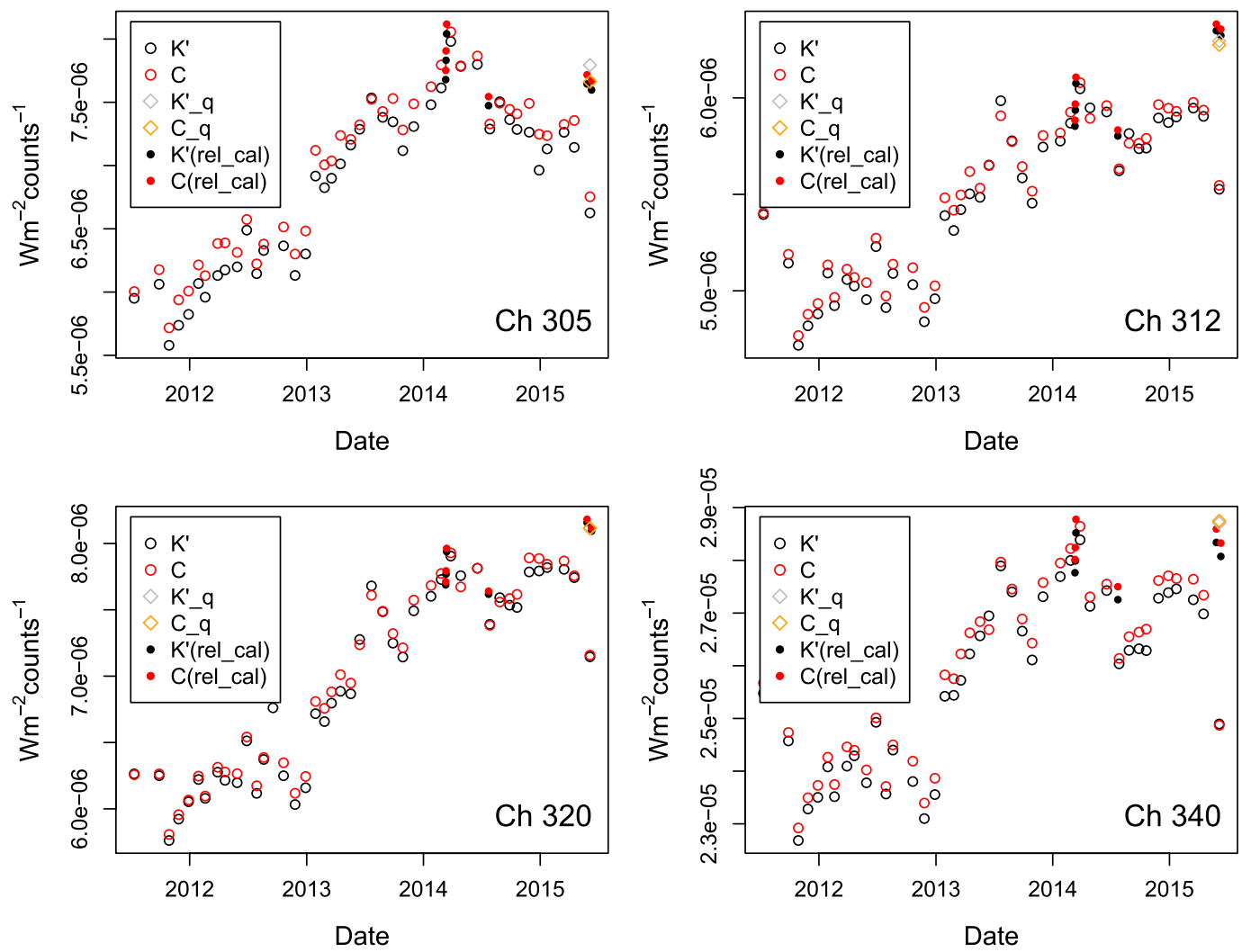

FIG. 3. Temporal evolution of $K_{i}^{\prime}$ and $C_{i}$ factors for all channels of the NILU-UV 119 multifilter radiometer; $K_{i}^{\prime}$ and $C_{i}$ for campaign 43 (open diamonds) are calculated from intercomparison with the QASUME unit. Sparse results from relative calibrations were included in the plots as solid points.

Linzhi, Tibet. For other instruments deployed in the Tibetan Plateau, drifts were smaller (between $10 \%$ and 15\%) (Norsang et al. 2014). For three NILU-UV instruments deployed in the New York area, sensitivity drifted between $10 \%$ and $20 \%$ for 305 , and up to $20 \%$ for channels 312, 320 and 340, in a 3-yr period (Fan et al. 2014).

Results from available relative calibrations performed during the period covered in this study are in agreement with results obtained by absolute intercomparisons against the Brewer 150 and QASUME unit within $2.1 \%, 2.9 \%, 2.9 \%, 4.0 \%$, and $5.9 \%$ for channels 305 , $312,320,340$, and $380 \mathrm{~nm}$, respectively (Fig. 3). Note that for campaign $43, K_{i}^{\prime}$ and $C_{i}$ derived from intercomparison with the Brewer 150 are not shown because this spectroradiometer malfunctioned in this particular campaign, not being reliable as reference for several weeks. However, results from relative calibration are in agreement with the absolute calibration factors calculated by intercomparison with the QASUME unit. Therefore, for campaign $43, K_{i}^{\prime}$ and $C_{i}$ values determined by relative calibrations are used, as they proved to be accurate.
The high-resolution temporal reconstruction of $K_{i}^{\prime}(t)$ and $C_{i}(t)$ from frequent sensitivity tracking (by absolute intercomparison in this particular case) improves the quality of the derived measurements: filter-weighted irradiance, UV dose rates and ozone. The reconstruction based on biennial standard campaigns $\left[K_{i}^{\prime} b(t), C_{i} b(t)\right]$ overestimates the absolute calibration term in between $1.4 \%$ and $4.6 \%$ as compared to the thorough reconstruction of $K_{i}^{\prime}(t)$, and in between $2.6 \%$ and $5.8 \%$ as compared to $C_{i}(t)$ (see Fig. 4). Applying absolute calibration terms obtained using low-temporal-resolution measurements in the calibration equations would lead to an overestimation in the $E_{i}(t)$ irradiance values. This result suggests that

TABLE 3. $K_{i}^{\prime} C_{i}$ relative range variation of $K_{i}^{\prime}$ and $C_{i}$ for all channels of the NILU-UV 119 instrument.

\begin{tabular}{ccc}
\hline \hline Channel & $K_{i}^{\prime}(\%)$ & $C_{i}(\%)$ \\
\hline 305 & 40 & 42 \\
312 & 30 & 30 \\
320 & 38 & 38 \\
340 & 23 & 23 \\
\hline
\end{tabular}




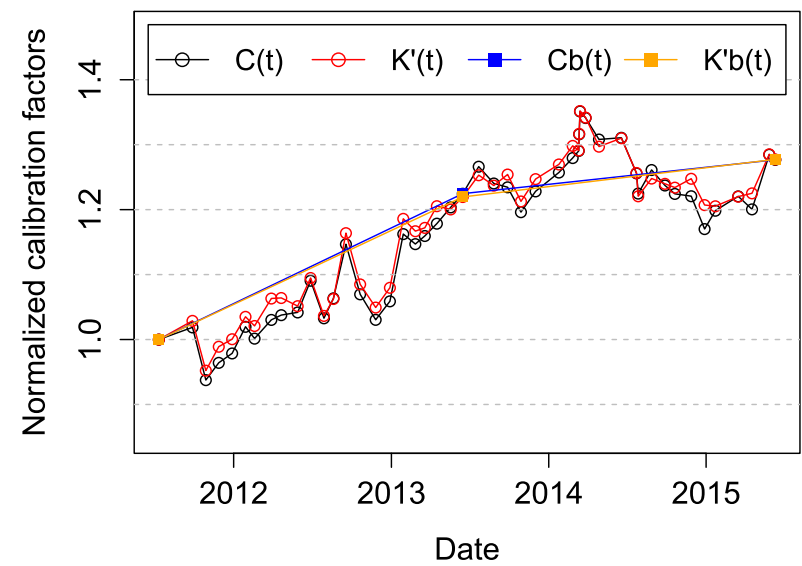

FIG. 4. Temporal reconstruction of normalized calibration factors based on biennial standard campaigns $\left[K_{i}^{\prime} b(t), C_{i} b(t)\right]$ or on frequent intercomparisons $\left[K_{i}^{\prime}(t), C_{i}(t)\right]$ for the NILU-UV 119 instrument, channel 305 .

frequent tracking of the sensitivity of these multifilter instruments is strongly recommended in order to guarantee the reliability of the irradiance data. Additionally, it is well known that the channels may drift upward and downward in a shorter time scale (Lakkala et al. 2005), an effect that could not be detected by periodic standard calibration campaigns distant in time.

\section{c. Empirical functions $f_{\text {in }}^{\prime}(\theta)$ and $f_{\text {in }}^{\prime}(\theta, \phi)$}

Once $C_{i}(t)$ values were determined, $k_{i j n}^{\prime}$ normalized values for each campaign were obtained from $k_{i j}^{\prime}$, following Eq. (7). A modeling subset (75\% of data) from $k_{i j n}^{\prime}$ dataset was fitted to a polynomial of third grade (Piedehierro et al. 2016). The remaining $25 \%$ of data were used for validation purposes. The root-meansquare error (RMSE) in its relative form was used to assess the goodness of the fittings. MABE statistics is calculated over the validation subset $\left(\mathrm{MABE}_{v}\right)$ and over the complete dataset $\left(\mathrm{MABE}_{t}\right)$, indicating the average of the absolute differences in both cases (Table 4).

RMSE values for $f_{i}^{\prime}(\theta)$ are higher than those reported by Piedehierro et al. (2016), which used data from a 10-day campaign. In the present work, $f_{i}^{\prime}(\theta)$ comes from a broader dataset, recorded under all-sky conditions

TABLE 4. Fitting and validation results for $f_{\text {in }}^{\prime}(\theta)$ functions for all channels.

\begin{tabular}{ccccc}
\hline & \multicolumn{2}{c}{ Fitting } & & \multicolumn{2}{c}{ Validation } \\
\cline { 2 - 3 } Channel & RMSE (\%) & & $\operatorname{MABE}_{v}(\%)$ & $\operatorname{MABE}_{t}(\%)$ \\
\hline 305 & 11.0 & & 5.8 & 5.7 \\
312 & 4.1 & & 2.7 & 2.7 \\
320 & 3.9 & & 2.5 & 2.5 \\
340 & 3.8 & 2.1 & 2.2 \\
\hline
\end{tabular}

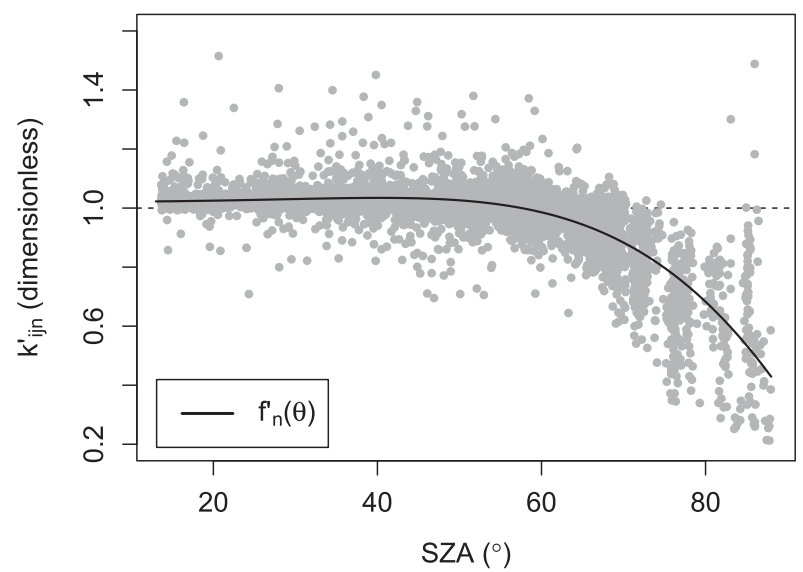

FIG. 5. $k_{i j n}^{\prime}$ values for channel 305 , jointly with $f_{\text {in }}^{\prime}(\theta)$ empirical function.

for almost four years, and therefore, data are expected to be more scattered. Specifically, relative RMSE values were $11 \%$ for channel 305 and around $4 \%$ for the remaining channels. The same behavior is found for $\mathrm{MABE}_{v}$ and $\mathrm{MABE}_{t}$, also higher values than those found by Piedehierro et al. (2016). Nevertheless, $\mathrm{MABE}_{v}$ and $\mathrm{MABE}_{t}$ are consistent, pointing out that the fitting model is appropriate for the entire study period as well.

In Fig. 5 the performance of $f_{305 n}^{\prime}(\theta)$ is shown, overlapping the $k_{305 j n}^{\prime}$ data for channel 305 , widely scattered for large SZA. This effect was previously detected by Piedehierro et al. (2016) where a partial explanation was given: the 305 channel performs differently in lowintensity irradiance scenarios, depending on the external temperature. That means that channel 305 is particularly affected by thermal offset, becoming relevant for measurements during rising and setting sun. Even though the temperature recorded by an internal sensor is stable during the operation of the instrument, there is still a temperature gradient inside the NILU-UV due to the external temperature, affecting the radiation sensors. This phenomenon is particularly relevant in the case of the dark signal evaluation and low irradiance intensity cases.

The dark signal or offset, calculated as the daily average of those data corresponding to $\mathrm{SZA}>110^{\circ}$, varies slightly from day to day, but this variation is less than $10 \%$. Variations in dark signal were actually found to be dependent on external temperature (note that the operation temperature is always stable at night). However, low-intensity raw measurements (corresponding to SZA larger than $75^{\circ}$ ) are still affected by external temperature even after being corrected from the offset effect by subtracting the night average dark signal value. Measurements of channel 305 taken under the same low 


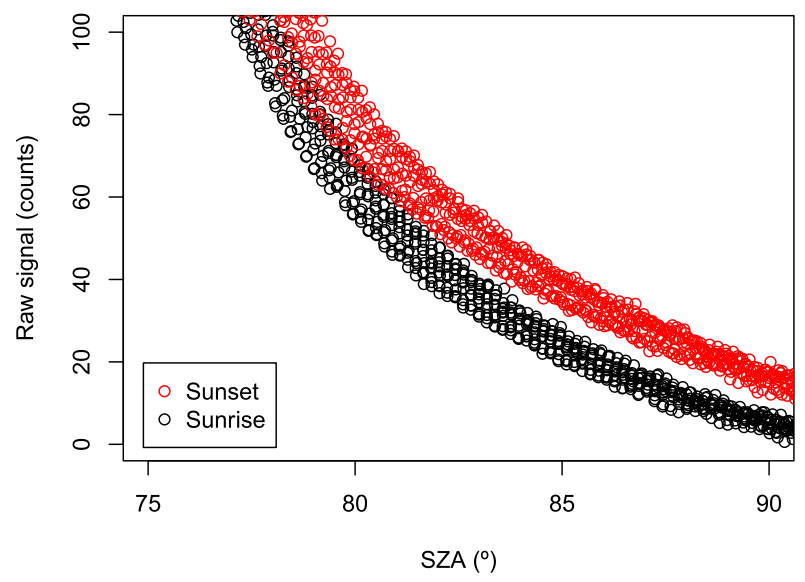

FIG. 6. The 1-min offset corrected raw measurements from channel 305 during campaign 3 period for large SZA. Black (red) symbols correspond to morning (evening) measurements.

intensity illumination are higher for increased external temperature. This effect is clearly illustrated in Fig. 6, where 1-min raw measurements (corrected from offset) from the NILU-UV's 305 channel are plotted against SZA for campaign 3. It can be seen that the scatterplot draws two branches: the upper one corresponding to setting sun, and the lower one to rising sun.

The asymmetry in the raw data is most likely due to the influence of external temperature: minimum temperatures are reached just before sunrise while external temperature is expected to be higher during sunset. The distinct performance of channel 305 for setting and rising sun likely explains much of the variability found in $k_{i j}^{\prime}$ for large SZA. Since $k_{i j}^{\prime}$ values corresponding to both situations were taken into account to obtain the empirical functions $f_{i}^{\prime}(\theta)$, the resulting functions describe an average performance.

To improve the performance of the empirical functions at large SZA, $k_{i j n}^{\prime}$ dataset is divided into two subsets: one corresponding to $\phi<180^{\circ}$ (including early morning measurements), and the other one corresponding to $\phi>180^{\circ}$ (including sunsetting measurements) (Iqbal 1983). The resulting subsets were fitted to obtain both empirical functions $f_{\text {in }}^{\prime}\left(\theta, \phi<180^{\circ}\right)$ and $f_{\text {in }}^{\prime}\left(\theta, \phi>180^{\circ}\right)$ following the same procedure described for $f_{\text {in }}^{\prime}(\theta)$. Fitting results are compiled in Table 5. Both subset fittings for channel 305 result in slightly different curves, presenting a stronger SZA dependence than those data corresponding to $\phi>180^{\circ}$ (Fig. 7). Thus, $R^{2}$ for this channel has increased from 0.61 to 0.74 for the fitting $f_{\text {in }}^{\prime}\left(\theta, \phi>180^{\circ}\right)$ compared to $f_{\text {in }}^{\prime}(\theta)$. In general, fitting and validation statistics are better for channel 305 and $f_{\text {in }}^{\prime}\left(\theta, \phi<180^{\circ}\right)$. For the remaining channels and $f_{\mathrm{in}}^{\prime}\left(\theta, \phi>180^{\circ}\right)$ fitting, the statistical values are practically the same.

With this artifact it is possible to partially correct the thermal offset effect without taking the real ambient temperature into account or without the need to carry out particular experiments to evaluate the thermal offset for this specific instrument. This methodology is especially relevant for channel 305 , in which the thermal offset plays a greater role due to the lowintensity irradiance values that occur naturally for shorter wavelengths.

The addition of the newly defined empirical functions results in the new version of $\mathrm{CC} 2$ model: $\mathrm{CC} 2(\phi)$ [Eq. (9)].

\section{d. Comparison with reference values}

Equations (4), (6), and (8) corresponding to long-term calibration methods $\mathrm{CC}(t), \mathrm{CC} 2(t)$, and $\mathrm{CC} 2(\phi)(t)$, respectively, were used to retrieve weighted-irradiance values for the period July 2011-June 2015. The $K^{\prime}(t)$ and $C(t)$ values were obtained by linearly interpolating the set of known $K^{\prime}$ and $C$ constants and the empirical functions.

The $E_{i}^{W}$ irradiance estimated by the NILU-UV 119 was compared against simultaneous values of the reference Brewer 150 over an independent subset of data. This subset consists of the remaining data not used in the campaigns selected to obtain $K^{\prime}(t), C(t), f_{\text {in }}^{\prime}(\theta)$, and $f_{\text {in }}^{\prime}(\theta, \phi)$.

In this comparison, MABE and MBE are calculated for the three long-term calibration methods: $\mathrm{CC}(t)$, $\mathrm{CC} 2(t)$, and $\mathrm{CC} 2(\phi)(t)$. This validation is performed for all channels, analyzing three different SZA ranges: (i) the complete SZA interval, (ii) $\mathrm{SZA}<65^{\circ}$, and (iii) SZA $>65^{\circ}$ (Table 6). In agreement with Piedehierro et al. (2016), these SZA ranges were selected taking into

TABLE 5. Fitting and validation results for $f_{\text {in }}^{\prime}\left(\theta, \phi<180^{\circ}\right)$ and $f_{\text {in }}^{\prime}\left(\theta, \phi>180^{\circ}\right)$ functions for all channels.

\begin{tabular}{|c|c|c|c|c|c|c|c|c|}
\hline \multirow[b]{3}{*}{ Channel } & \multicolumn{4}{|c|}{$f_{\text {in }}^{\prime}\left(\theta, \phi<180^{\circ}\right)$} & \multicolumn{4}{|c|}{$f_{\text {in }}^{\prime}\left(\theta, \phi>180^{\circ}\right)$} \\
\hline & \multicolumn{2}{|c|}{ Fitting } & \multicolumn{2}{|c|}{ Validation } & \multicolumn{2}{|c|}{ Fitting } & \multicolumn{2}{|c|}{ Validation } \\
\hline & $R^{2}$ & RMSE (\%) & $\operatorname{MABE}_{v}(\%)$ & $\operatorname{MABE}_{t}(\%)$ & $R^{2}$ & RMSE (\%) & $\operatorname{MABE}_{v}(\%)$ & $\operatorname{MABE}_{t}(\%)$ \\
\hline 305 & 0.42 & 7.2 & 4.0 & 3.9 & 0.74 & 11 & 5.9 & 6.0 \\
\hline 312 & 0.66 & 4.2 & 2.5 & 2.5 & 0.17 & 4.0 & 2.6 & 2.7 \\
\hline 320 & 0.12 & 4.2 & 2.5 & 2.5 & 0.24 & 3.7 & 2.4 & 2.4 \\
\hline 340 & 0.021 & 3.9 & 2.1 & 2.2 & 0.015 & 3.7 & 2.2 & 2.1 \\
\hline
\end{tabular}




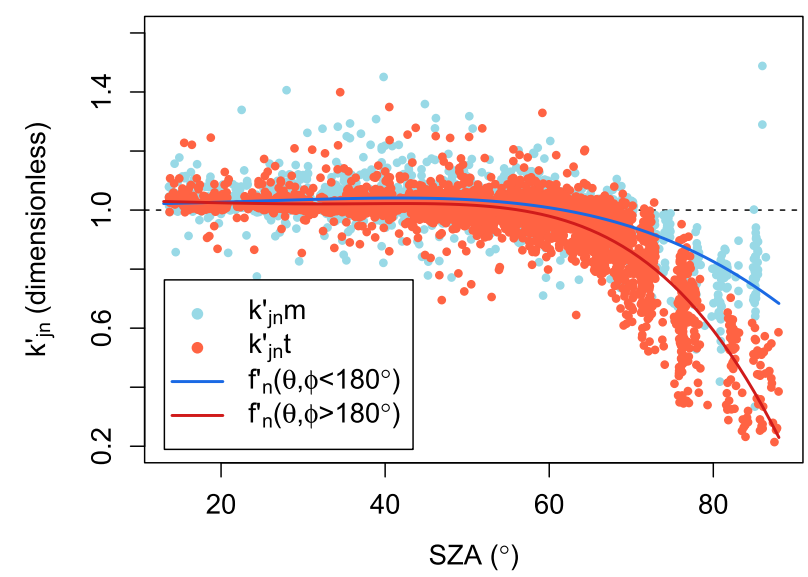

FIG. 7. The $f_{305 n}^{\prime}\left(\theta, \phi<180^{\circ}\right)$ and $f_{305 n}^{\prime}\left(\theta, \phi>180^{\circ}\right)$ empirical functions overlapping $k_{305 j n}^{\prime}\left(\phi<180^{\circ}\right)$ and $k_{305 j n}^{\prime}\left(\phi>180^{\circ}\right)$ values for channel 305 .

account the limitations that all methods might present beyond $\left.65^{\circ}: 1\right) \mathrm{CC}$ method is not intended to be applied for SZA $>65^{\circ}$ for channel 305 ; 2$) f_{i}^{\prime}(\theta)$ from $\mathrm{CC} 2$ methods performs slightly different for SZA larger than $65^{\circ}$.

Compared to $\mathrm{CC}, \mathrm{CC} 2$ reduces the $\mathrm{MBE}$ in its longterm application for the entire SZA interval, and particularly for SZA $>65^{\circ}$. This reduction is more evident for channel 305 , decreasing from $25 \%$ to $1.5 \%$ (SZA > $65^{\circ}$ ). The $\mathrm{MBE}_{v}$ value $\left(\mathrm{SZA}>65^{\circ}\right.$ ) associated to 305 channel for $\mathrm{CC}$ method agrees with the values found by Johnsen et al. (2008a) for an uncorrected UV-B channel. This difference comes from the inapplicability of $K_{305}^{\prime}$ beyond $65^{\circ}$. For the remaining channels, the improvement is almost only noticeable at large SZA, with $3 \%$ average reductions for channels 312 and 320, and the reduction for channel 340 being even smaller. The application of $\mathrm{CC} 2$ also brings a reduction on MABE for all channels, but the strongest effect is seen for channel 305 , where MABE is reduced from $26 \%$ to $12 \%$ (SZA > $\left.65^{\circ}\right)$. Thus, total SZA MABE diminished from $8.0 \%$ to $5.5 \%$.

The performance of $\mathrm{CC}$ and $\mathrm{CC} 2$ in the long term reproduces the results of the short-term application analyzed by Piedehierro et al. (2016). While MBE validation values are quite similar for both studies, MABE statistics tend to be higher for all channels and the entire SZA range when the methods are applied at a long-term scale. This is probably due to the longer data series used in this study, with data under all-sky conditions being included.

The new version of the $\mathrm{CC} 2$ method $[\mathrm{CC} 2(\phi)]$ reduces MABE and MBE (11\% and $0.84 \%$, respectively) for channel 305 at large SZA.

The greatest improvements performed by $\mathrm{CC} 2(\phi)$ are thus observed for channel 305 , since it is the most affected by thermal offset. This effect can be clearly seen in Fig. 8. It must be noted that the relative differences for channel 305 are somehow magnified due to the lower intensities measured for short wavelengths. $\mathrm{CC} 2$ and $\mathrm{CC} 2(\phi)$ especially reduce the relative differences with the reference values for channel 305. For the remaining channels, the improvement is negligible.

The long-term application of $\mathrm{CC} 2$ and $\mathrm{CC} 2(\phi)$ agrees with results found by Johnsen et al. (2008a), with relative differences being reduced to $\pm 2 \%$ by introducing an empirical correction. However, it must be noted that

TABLE 6. Calibration functions comparison for all channels.

\begin{tabular}{|c|c|c|c|c|c|c|}
\hline \multirow[b]{2}{*}{ Methods } & \multicolumn{2}{|c|}{ Total SZA } & \multicolumn{2}{|c|}{$\mathrm{SZA}<65^{\circ}$} & \multicolumn{2}{|c|}{$\mathrm{SZA}>65^{\circ}$} \\
\hline & $\operatorname{MBE}_{v}(\%)$ & $\operatorname{MABE}_{v}(\%)$ & $\operatorname{MBE}_{v}(\%)$ & $\operatorname{MABE}_{v}(\%)$ & $\operatorname{MBE}_{v}(\%)$ & $\operatorname{MABE}_{v}(\%)$ \\
\hline \multicolumn{7}{|c|}{ Channel 305} \\
\hline $\mathrm{CC}$ & 5.8 & 8.0 & 0.31 & 3.6 & 25 & 26 \\
\hline $\mathrm{CC} 2$ & 0.39 & 5.5 & 0.11 & 3.9 & 1.5 & 12 \\
\hline $\operatorname{CC} 2(\phi)$ & 0.24 & 5.2 & 0.095 & 3.7 & 0.84 & 11 \\
\hline \multicolumn{7}{|c|}{ Channel 312} \\
\hline $\mathrm{CC}$ & 0.24 & 3.2 & -0.54 & 3.0 & 3.2 & 4.3 \\
\hline $\mathrm{CC} 2$ & 0.16 & 3.0 & 0.095 & 2.9 & 0.42 & 3.3 \\
\hline $\operatorname{CC} 2(\phi)$ & 0.16 & 2.9 & 0.11 & 2.8 & 0.35 & 3.1 \\
\hline \multicolumn{7}{|c|}{ Channel 320} \\
\hline $\mathrm{CC}$ & 0.17 & 3.1 & -0.65 & 2.7 & 3.3 & 4.3 \\
\hline $\mathrm{CC} 2$ & 0.07 & 2.8 & 0.059 & 2.7 & 0.11 & 2.9 \\
\hline $\operatorname{CC} 2(\phi)$ & 0.095 & 2.7 & 0.081 & 2.7 & 0.15 & 2.8 \\
\hline \multicolumn{7}{|c|}{ Channel 340} \\
\hline $\mathrm{CC}$ & 0.22 & 2.5 & 0.024 & 2.5 & 0.95 & 2.5 \\
\hline $\mathrm{CC} 2$ & 0.18 & 2.5 & 0.18 & 2.5 & 0.18 & 2.3 \\
\hline $\operatorname{CC} 2(\phi)$ & 0.18 & 2.5 & 0.19 & 2.5 & 0.17 & 2.3 \\
\hline
\end{tabular}




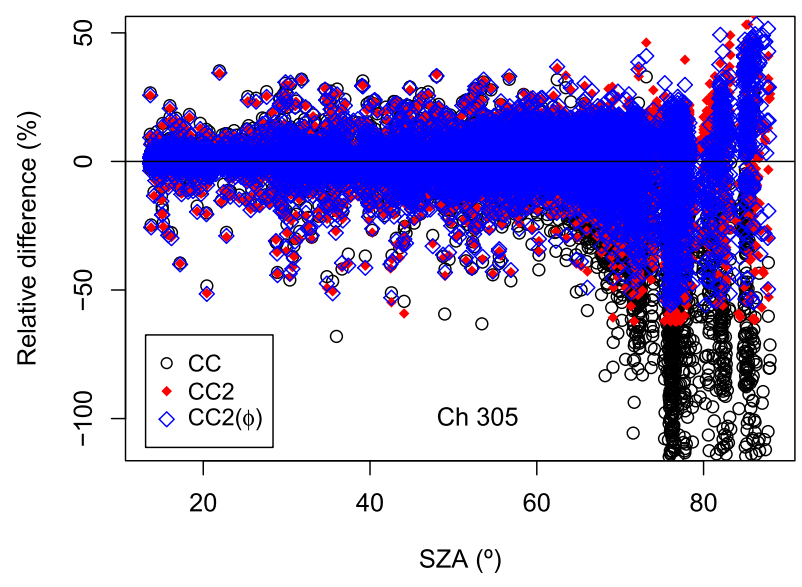

FIG. 8. Agreement between calibration methods and reference values in terms of relative differences for channel 305.

some scattering in channel 305 still remains for large SZA. The long-term application of DB method for GUV instruments as reported by Bernhard et al. (2005) has uncertainties of $\pm 5 \%$ (for SZA $<85^{\circ}$ ), so the results here obtained by the application of $\mathrm{CC}$, $\mathrm{CC} 2$, and $\mathrm{CC} 2(\phi)$ constitute an improvement compared to those by Bernhard et al. (2005).

\section{Conclusions}

In this paper, three calibration methods [CC, $\mathrm{CC} 2$, and $\mathrm{CC} 2(\phi)]$ are adapted to be applied in the long term, with special emphasis given to the temporal variations of the absolute calibration term. While CC method can be straightforwardly generalized by including the temporal evolution of the absolute calibration factor $K^{\prime}(t), \mathrm{CC} 2$ requires the normalization of its empirical function by introducing a factor $C_{i}$, which can be considered as the absolute calibration factor. The effect of the temperature-dependent offset was detected in the determination of the normalized $f_{\text {in }}^{\prime}(\theta)$, since $k_{i j}^{\prime}$ presented distinct performance for different ambient temperatures under the same radiation conditions. Data were split into morning and evening subsets of measurements to obtain $f_{\text {in }}^{\prime}(\theta, \phi)$, achieving better angular corrections for channel $305 \mathrm{~nm}$. This new version of the model $\mathrm{CC} 2$ constitutes the new $\mathrm{CC} 2(\phi)$ model.

In all three cases $[\mathrm{CC}(t), \mathrm{CC} 2(t), \mathrm{CC} 2(\phi)(t)]$ the new formulations allowed us to match standard calibrations with relative calibrations. The use of relative calibrations contributes to the tracking of the absolute sensitivity of the channels, that is, to define the temporal evolution of $K^{\prime}(t)$ and $C(t)$.

In this work, the temporal variation of $K^{\prime}(t)$ and $C(t)$ was assessed by absolute intercomparison against a reference Brewer spectroradiometer, obtaining monthly values for these factors. Changes in sensitivity were found to depend on the channel, varying in time as well. Thus, the observed total drift of the NILU-UV 119 in a 4-yr period ranged between $23 \%$ and $42 \%$. Given these results, intermediate calibration between biennial standard calibrations are needed to provide measurements of multifilter instruments of acceptable accuracy.

The comparison of the three calibration methods was performed over an independent validation dataset. Weighted irradiances were obtained by every method and compared to reference values given by the Brewer 150 spectrophotometer, for different SZA intervals.

The long-term application of CC2 clearly improves the accuracy of the irradiance measurements taken by the NILU-UV in all SZA range, but particularly for SZA $>65^{\circ}$. This long-term generalization also highlights the limitations of the COSCOR functions. The greatest improvement is, once again, found for channel 305. Better estimations for the lowest wavelength channel leads to improvements in those products using this channel, such as Commission Internationale de l'Éclairage (CIE) dose rate (Dahlback 1996) and total ozone column (Stamnes et al. 1991).

The CC2 $(\phi)$ version has a small but clear effect on channel 305 for large SZA, reducing the uncertainty when comparing to the reference values.

Summarizing, results derived from this study indicate that for a long-term application, calibration methods based on empiric functions constitute an improved option for irradiance estimation using multifilter instruments, particularly for large SZA. Even though these methodologies may be applicable to other multifilter instruments, it would be advantageous to test them for different instrumentation with similar features. Of course, the calibration functions and sensitivity drifts are instrument dependent.

We have confirmed that actual short-term variations in sensitivity (as proven by frequent absolute calibrations against a Brewer spectroradiometer) occur to multifilter instruments. The drifts of multifilter instruments could also be tracked by performing frequent relative calibrations if no collocated spectrometer is available on site. In fact, the three relative calibrations performed during the study period covered by this work matched the absolute calibrations against the Brewer spectroradiometer and QASUME unit within a few percent for all channels. The low uncertainty associated to the relative calibration protocol, followed by the good agreement of the sensitivity changes estimated by the performed relative calibrations, gives us reasons to believe that this methodology could be used to obtain an estimation for the short-term changes in sensitivity affecting multifilter instruments. 
Finally, the effect of the thermal offset on the raw measurements during low radiation conditions should be evaluated and analyzed in depth in order to remove it from those channels affected by it.

Acknowledgments. Ana A. Piedehierro thanks Junta de Extremadura and Fondo Social Europeo for her predoctoral grant. This work was partially supported by Ministerio de Economía y Competitividad (Spanish Government) through coordinated Projects CGL201456255-C2 and by Junta de Extremadura and FEDER Funds GR15137 and IB18092.

\section{REFERENCES}

Bernhard, G., C. R. Booth, and J. C. Ehramjian, 2005: Real-time ultraviolet and column ozone from multichannel ultraviolet radiometers deployed in the National Science Foundation's ultraviolet monitoring network. Opt. Eng., 44, 041011, https:// doi.org/10.1117/1.1887195.

,,$---\longrightarrow$, and V. V. Quang, 2008: NSF Polar Programs UV spectroradiometer network 2006-2007. Biospherical Instruments Inc. Operations Rep., Vol. 16.0, 265 pp.

Dahlback, A., 1996: Measurements of biologically effective UV doses, total ozone abundances and cloud effects with multichannel, moderate bandwidth filter instruments. Appl. Opt., 35, 6514-6521, https://doi.org/10.1364/AO.35.006514.

Díaz, S., and Coauthors, 2011: Data quality objectives (DQO) for solar ultraviolet radiation measurements (Part I): Scanning spectral and broadband instruments. WMO Global Atmosphere Watch Programme Rep. 198, 21 pp.

Fan, L., W. Li, A. Dahlback, J. J. Stamnes, S. Englehardt, S. Stamnes, and K. Stamnes, 2014: Comparisons of three NILU-UV instruments deployed at the same site in the new York areas. Appl. Opt., 53, 3598-3606, https://doi.org/10.1364/ AO.53.003598.

Gröbner, J., 2003: Improved entrance optic for global irradiance measurements with a Brewer spectrophotometer. Appl. Opt., 42, 3516-3521, https://doi.org/10.1364/AO.42.003516.

_, M. Blumthaler, and W. Ambach, 1996: Experimental investigation of spectral global irradiance measurement errors due to a non ideal cosine response. Geophys. Res. Lett., 23, 2493 2496, https://doi.org/10.1029/96GL02380.

—_, G. Hülsen, L. Vuilleumier, M. Blumthaler, J. M. Vilaplana, D. Walker, and J. E. Gil, 2006: Report of the PMOD/WRC-COST calibration and intercomparison of erythemal radiometers. European Cooperation in Science and Technology Rep., 108 pp.

Høiskar, B. A. K., and Coauthors, 2003: Multichannel moderatebandwidth instrument for measurement of the ozone-column amount, cloud transmittance and ultraviolet dose rates. Appl. Opt., 42, 3472-3479, https://doi.org/10.1364/AO.42.003472.

Hossaini, R., M. P. Chipperfield, S. A. Montzka, A. Rap, S. Dhomse, and W. Feng, 2015: Efficiency of short-lived halogens at influencing climate through depletion of stratospheric ozone. Nat. Geosci., 8, 186-190, https://doi.org/10.1038/ngeo2363.

Iqbal, M., 1983: An Introduction to Solar Radiation. Academic Press, 408 pp.
Johnsen, B., and Coauthors, 2008a: Intercomparison of global UV index from multiband filter radiometers: Harmonization of global UVI and spectral irradiance. WMO Tech. Rep. WMO/TD-1454, 61 pp.

— of UV index measurement from multiband filter radiometers. J. Geophys. Res., 113, D15206, https://doi.org/10.1029/ 2007JD009731.

Kazantzidis, A., A. Bais, C. Topaloglou, K. Garane, M. Zempila, C. Meleti, and C. Zerefos, 2006: Quality assurance of the Greek UV network: Preliminary results from the pilot phase operation. Proc. SPIE, 6362, 636229, https://doi.org/10.1117/ 12.689798 .

Lakkala, K., and Coauthors, 2005: Quality assurance of the solar UV network in the Antarctic. J. Geophys. Res., 110, D15101, https://doi.org/10.1029/2004JD005584.

Lucas, R. M., M. Norval, R. E. Neale, A. R. Young, F. R. de Gruijl, Y. Takizawa, and J. C. van der Leun, 2015: The consequences for human health of stratospheric ozone depletion in association with other environmental factors. Photochem. Photobiol. Sci., 14, 53-87, https://doi.org/10.1039/C4PP90033B.

Meinander, O., T. Koskela, K. Lakkala, A. Redondas, C. Torres, E. Cuevas, G. Deferrari, and J. Gröbner, 2004: Antarctic NILU-UV network linked to QASUME and NSF irradiance scales. Quadrennial Ozone Symp., Kos, Greece, International Ozone Commission, 1128-1129.

NILU Products, 1999: The NILU-UV relative lamp unit: User's manual. NILU Products Rep., 6 pp.

Norsang, G., L. Kocbach, W. Tsoja, J. J. Stamnes, A. Dahlback, and P. Nema, 2009: Ground-based measurements and modeling of solar UV-B radiation in Lhasa, Tibet. Atmos. Environ., 43, 1498-1502, https://doi.org/10.1016/j.atmosenv.2008.11.048.

— surements of solar UV radiation at four sites on the Tibetan Plateau. Appl. Opt., 53, 736-747, https://doi.org/10.1364/ AO.53.000736.

Piedehierro, A. A., 2016: Medida y modelización de la radiación ultravioleta mediante el uso de radiómetros multicanal. Ph.D. thesis, Universidad de Extremadura, 254 pp.

- M. L. Cancillo, A. Serrano, M. Antón, and J. M. Vilaplana, 2016: Global sky irradiance calibration of multifilter UV radiometers. J. Geophys. Res. Atmos., 121, 427-438, https:// doi.org/10.1002/2015JD023935.

Seckmeyer, G., A. Bais, G. Bernhard, M. Blumthaler, B. Johnsen, K. Lantz, and R. McKenzie, 2010: Instruments to measure solar ultraviolet radiation. Part 3: Multi-channel filter instruments. WMO Rep. WMO/TD-1537, 51 pp.

Stamnes, K., J. Slusser, and M. Bowen, 1991: Derivation of total ozone abundance and cloud effects from spectral irradiance measurements. Appl. Opt., 30, 4418-4426, https://doi.org/ 10.1364/AO.30.004418.

Vilaplana, J. M., 2004: Medida y análisis del ozono y de la radiación solar ultraviolet en INTA-El Arenosillo. Ph.D. thesis, Universidad de Valladolid, $247 \mathrm{pp}$.

Webb, A., J. Gröbner, and M. Blumthaler, 2006: A practical guide to operating broadband instruments measuring erythemally weighted irradiance. WMO and European Cooperation in Science and Technology Rep. EUR 22595, 26 pp.

WMO, 2014: Scientific assessment of ozone depletion: 2014. WMO Global Ozone Research and Monitoring Project Rep., 416 pp. 